\title{
Endoscopic Thyroid Surgery through Breast and Axillary Approach
}

\section{Gyan Chand, Amit Agarwal}

\begin{abstract}
Thyroid surgery was introduced since ages; it was initially started with large incision in the neck. Due to advancement in technology the minimally invasive surgery has been introduced for all organs. This technology is introduced in the thyroid surgery too. Different approaches have been established including minimally invasive video assisted, endoscopic, robotic and natural orifice thyroid surgery. Among these different approaches of endoscopic thyroid surgery, the breast and axillary approach is most acceptable and easy to perform. Here I am going to describe this technique of endoscopic thyroid surgery.
\end{abstract}

Keywords: Thyroid surgery, Endoscopic surgery techniques, Thyroidectomy.

How to cite this article: Chand G, Agarwal A. Endoscopic Thyroid Surgery through Breast and Axillary Approach. World J Endoc Surg 2013;5(3):85-88.

\section{Source of support Nil}

Conflict of interest: None

\section{INTRODUCTION}

Thyroid surgery was introduced by Theodor Kocher in 1996, after him there is continuous technical advancement in thyroid surgery, that development is possible only due to better understanding of thyroid embryology, anatomy and pathophysiology of disease process. There is evolution in techniques of capsular dissection with preservation of recurrent laryngeal nerve and parathyroid. There is also advancement in vessels sealing energy devices, including bipolar cautery, Ligasure and Harmonic scal pel. D ue to these advancements in technology, the feasibility and acceptance of conventional surgery to minimally invasive surgery that includes video assisted to total endoscopic thyroid surgery has been increased among the thyroid surgeons as well as patients. ${ }^{2-4}$ Endoscopic neck surgery was first develop for parathyroidectomy by Gagner and Huscher et al in 1996 and 1997 respectively. ${ }^{1,5}$ There are different approaches for this endoscopic thyroid surgery including, cervical approach, axillary approach, breast approach and chest wall approach . A mong these approaches the axillary and breast approach is most popular and it was originally described by Ohgami et al. ${ }^{6}$ This technique is cosmetically most acceptable.

This manuscript describes our approach to endoscopic thyroid surgery through breast and axillary approach. This approach is most suitable for the single small thyroid nodule less than four centimeters and benign on cytology. A fter a fair amount of experience one can operate larger goiters with bilateral disease and papillary thyroid cancer also.

\section{SURGICAL TECHNIQUE}

\section{Instruments}

This technique is very simple, it requires only a standard set of laparoscopic instruments, which includes telescopes, common gas insufflators, light source and routine hand instruments. For dissection, we use the electro cautery, suction machine and ultrasonic vessel sealing and cutting device.

\section{Preoperative Preparations}

All patients should be adequately preoperative prepared as for the open surgery with care for preoperative comorbid conditions like diabetes, hypertension and respiratory disease. Patients' conditions should be optimized before surgery with medications.

\section{Anesthesia}

All patients require surgery under general anesthesia with single lumen flexometallic endotracheal tubes.

The hair should be removed from neck including axilla up to upper part of abdomen especially in male patients.

\section{Position}

The patient put on supine positions at 30 degree reverse trendel enburg position with sandbag under the shoulder to give extension over the neck and head is supported by head ring. The ipsilateral arm is extended up to $90^{\circ}$ to 120 .

The arm is well padded and strapped in position. The neck, chest and ipsilateral arm is cleaned well with savlon soap solution sprit and povidone iodine lotion.

\section{Skin Markings}

A fter proper draping, the surface marking of clavicle, sternocleidomastoid muscle (SCM), midline of neck and tumor is done with skin marking pen.

Incision site is marked: First $10 \mathrm{~mm}$ port just posterior to anterior axillary line (AAL) in the axilla near lower hairline, another $10 \mathrm{~mm}$ port marking at the superior-medial 
periareolar site on ipsilateral breast. Third $5 \mathrm{~mm}$ port is marked here to in the AAL $5 \mathrm{~cm}$ above to first port (Fig. 1).

\section{Port Placement}

1. A fter surface marking: the first $12 \mathrm{~mm}$ transverse incision is given parallel in skin crease in the axilla, the incision is deepened with artery forceps; a tunnel is created by pushing $10 \mathrm{~mm}$ trocar bluntly into the subcutaneous plane toward the midpoint of mid line of neck medial border of SCM. Then withdraw the trocar need to be corrected bel ow the clavicle level and now connect with $\mathrm{CO}_{2}$ insufflations with pressure at $6 \mathrm{~mm} \mathrm{Hg}$. Now telescope is put in $10 \mathrm{~mm}$ port after white balancing is given.

2. N ow another $10 \mathrm{~mm}$ incision at ipsilateral areolar margin for another port. A fter the incision, create subcutaneous plane toward neck and then pass the $10 \mathrm{~mm}$ cannula bluntly in subcutaneous plane toward the ipsilateral neck side and reach up to the first $12 \mathrm{~mm}$ blind tunnel and view with the telescope.

3. Now another $5 \mathrm{~mm}$ skin crease incision above the first port in AAL and create a small subcutaneous space with blunt artery forceps and pass a $5 \mathrm{~mm}$ trocar bluntly in subcutaneous plan directing it toward the ipsilateral neck side into the $10 \mathrm{~mm}$ tunnel.

\section{Subplatysmal Space Creation}

Once all the three ports have been created, a subcutaneous tunnel is made in the subplatysmal plane in the neck. The space is created laterally beyond the lateral border of SCM , superiorly up to the level of hyoid bone and medially up to the mid line and inferiorly beyond the suprasternal notch. This dissection is very crucial and careful use of

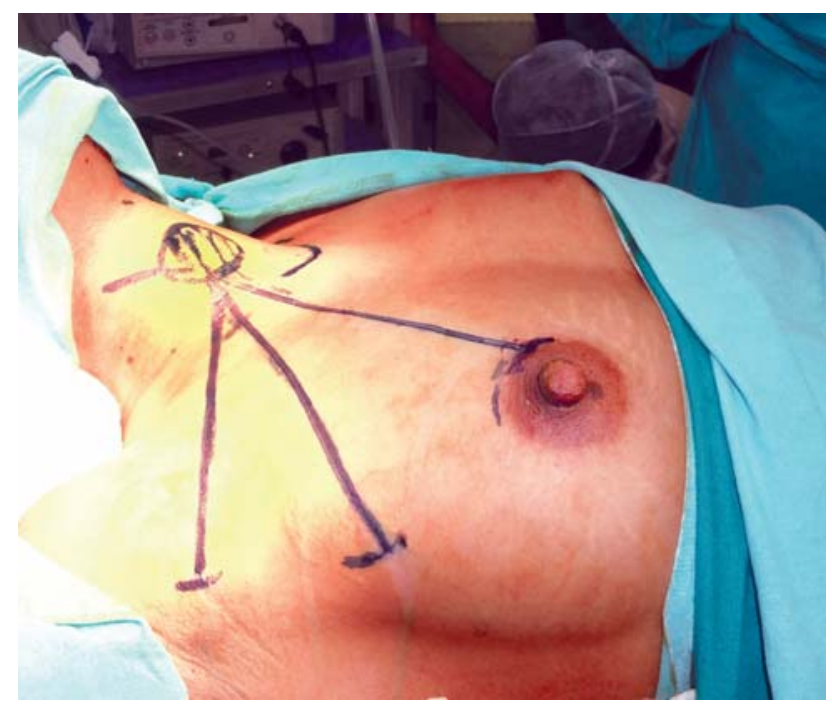

Fig. 1: Skin marking for the port placement electro-cautery is required because sometime the anterior jugular vein or lateral jugular vein is injured and causing lot of bleeding, so one can lose the plane of dissection and may get into the trouble.

\section{Dissection of Strap Muscles}

A fter the creation strap of adequate space for working the camera is handled by camera assistant (CA). The SCM is held with the grasper and space is created between the SCM and strep muscle. This space creation is started at the junction of upper $2 / 3 \mathrm{rd}$ and lower $1 / 3 \mathrm{rd}$ of SCM and proceeds upward with the help of electrocautery hook; once upper and lower ends are dissected then depth up to the visceral surface of thyroid lobe is dissected. N ow the strap muscle is carefully dissected from the thyroid lobe with the help of grasper and electrocautery hook.

\section{Dissection of Inferior Pole and Isthmus}

A fter mobilizing the strap muscle from the visceral surface of thyroid, middle thyroid vein is searched for and if it is present, coagulated and cut with ultrasonic devices. Then dissection is continued close to the thyroid gland inferiorly to handle the inferior vascul ar pedicle with ultrasonic vessel seal ing and cutting devices. A fter cutting the inferior pedicle vessels, move toward the isthmus and cut the isthmus.

\section{Lateral Dissection}

The thyroid is now lifted up and medially to visualize the recurrent laryngeal nerve (RLN), RLN is identified and protected. The inferior parathyroid is identified inferiomedial to $R L N$ identified and preserved. The inferior thyroid artery is secured properly with ultrasonic vessel sealing device. During this dissection care to be taken, not to injure the $R L N$ and parathyroid specially when tubercle of zuckerkandl is enlarged. The endoscopic magnification makes this step easier.

\section{Upper Pole Dissection}

Now the lobe is dissected out from the trachea and the gland is now pulled down to dissect the superior pole. The superior pole vessels are either clipped or directly coagulated and cut with the ultrasonic vessel sealing device near the upper pole of the thyroid lobe to preserve the external branch of superior laryngeal nerve.

\section{Dissection Near Trachea}

A fter managing the large vessels, the small vessels are also managed with ultrasonic device, now the upper pole of lobe is retracted downward and medially identify the superior parathyroid gland. 
The superior parathyroid is identify and preserve, then cut the berry's ligament near the trachea and al so few small attachment to the trachea is managed with the ultrasonic vessel sealing.

If the nodule in the upper pole of lobe, it is some time difficult to manage and you need to cut few fibers of strap muscle to reach the upper vascular practice.

In hemithyroidectomy, there is no need to suture the cut end of isthmus when you cut with ultrasound vessel sealing device.

For total thyroidectomy the similar procedure is repeated on contralateral sides with similar manner and position. The operating surgeon have to perform surgery from opposite side.

\section{Specimen Retrieval and Closure}

Both dissected lobe is kept in endo bag and taken out from one axillary port. Sometimes when the specimen is large, then the tunnel of axillary port is dilated with large artery forceps.

Proper homeostasis is secured and one can put hemostatic gel foam or absorbable gauge on both sides of trachea. Now negative pressure tube drain is kept through the axillary port. A ll ports side is closed with the subcuticular suture (Fig. 2).

\section{Postoperative Care}

Postoperative care is same as conventional open thyroid surgery. Drain is removed after 48 to 72 hours. For hemi thyroidectomy most of our patients are discharged within 24 hours and for total thyroidectomy they are discharged after drain output is low and no sign of hypocalcemia. For women, we recommend them to wear a sports brassiere during the first month postoperative to protect the incision and to make free form discomfort (Fig. 3).

\section{DISCUSSION}

The overall outcome with this technique is comparable with the other endoscopic thyroid surgery. The postoperative pain after 1 to 3 days of surgery is less and mean drainage period is put 3 to 4 days after surgery and seroma may be present in few cases. ${ }^{7}$

Other approaches include bilateral areolar approach (BAA ). Hur SM et al have operated 88 patients with benign tumors of any size or papillary thyroid microcarcinomas, the mean operation times were [121.7 \pm 24.5 vs $102.6 \pm$ 25 minutes for lobectomy $(p<0.05)$ and $162.5 \pm 36.1$ vs $131 \pm 28$ minutes for total thyroidectomy $(p<0.05)$ respectively]. There were no significant differences in the duration of hospitalization, amount of drainage from the surgical sites, and occurrence of postoperative complications. ${ }^{8}$

A nother endoscopic thyroidectomy via bilateral axillobreast approach (BABA), Choi JY et al presented 512 patients with thyroid diseases, who underwent $B A B A$ endoscopic thyroidectomy. A total of 397 had a malignant tumor and 115 had benign thyroid disease. M ean operation time was $151.2 \pm 38.1$ minutes for total and near-total thyroidectomy, and $141.7 \pm 50.1$ minutes for subtotal thyroidectomy and lobectomy. Regarding postoperative complications, transient hypocalcemia occurred in 31.1\% of patients and permanent hypoparathyroidism occurred in $4.2 \%$ of patients. Transient hoarseness occurred in $20.3 \%$ of patients, and permanent vocal cord palsy occurred in $1.7 \%$. M ean hospital stay after operation was $3.34 \pm 0.8$ days

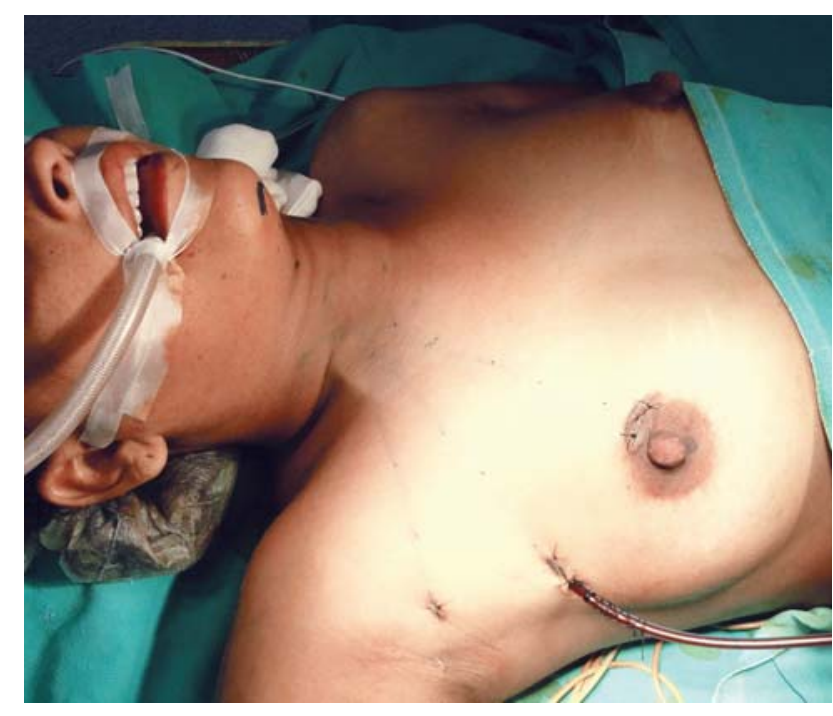

Fig. 2: After closure of wound

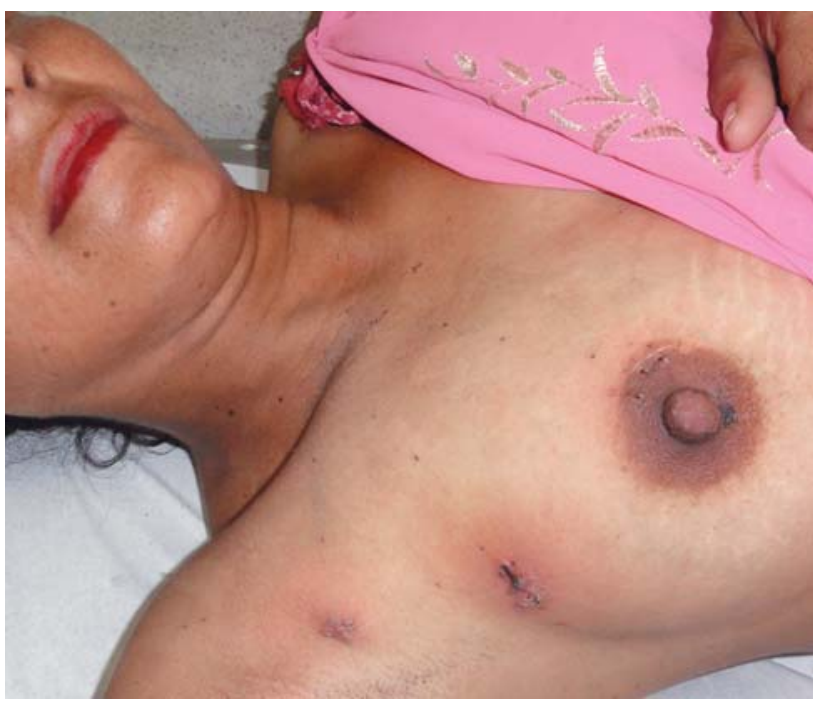

Fig. 3: Four weeks after surgery 
(range 3-7 days), and mean follow-up period was $57.1 \pm 17.6$ months (range 38.5-71.7 months). They concluded that endoscopic thyroidectomy via bilateral axillo-breast approach is a safe and effective method that gives good surgical completeness, a low rate of postoperative complications and recurrence, and an excellent cosmetic result. ${ }^{9}$

In summary these endoscopic techniques are becoming popular in A sia and well accepted with good cosmetic outcome and comparable complications.

\section{REFERENCES}

1. Huscher CS, Chiodini S, Napolitan C, et al. Endoscopic right thyroid lobectomy. Surg Endosc 1997;11:877.

2. M iccoli P, Rago R, M assi $M$, et al. Standerd versus videoassisted thyroidectomy: a prospective randomized study. Surgery 130;1039-1043.

3. Gal I, Solymosi T, Szabo, et al. M inimally invasive video assisted thyroidectomy and conventional thyroidectomy: a prospective randomized study. Surg Endosc 2008;22:2245-2449.

4. Miccoli P, Berti P, Frustaci GL, et al. Video-assisted thyroidectomy: indications and results. L angenbeck A rch Surg 2006;391:68-71.

5. Gagner M . Endoscopic subtotal parathyroidectomy in patients with primary hyperparathyroidism. Br J Surg 1996;83:875
6. Ohgami M, Ishii A, A isawa $Y$, et al. Scarless endoscopic thyroidectomy: breast approach for better cosmesis. Surg L aparosc Endosc Percutan Tech 10:1-4.

7. Lee MC, Mo JA, Choi IJ, Lee BC, Lee GH. New endoscopic thyroidectomy via a unilateral axillo-breast approach with gas insufflation: preliminary report. Head Neck 2013 A pr;35(4): 471-476.

8. Hur SM, Kim SH, Lee SK, Kim WW, Choe JH, Lee JE, K im $J \mathrm{H}, \mathrm{N}$ am SJ , Y ang J H, Kim J S. N ew endoscopic thyroidectomy with the bilateral areolar approach: a comparison with the bilateral axillo-breast approach. Surg L aparosc Endosc Percutan Tech. 2011 Oct;21(5):e219-224.

9. Choi JY, Lee KE, Chung KW, Kim SW, Choe JH, Koo do H Kim SJ, Lee J, Chung YS, Oh SK, Y oun YK. Endoscopic thyroidectomy via bilateral axillo-breast approach (BABA): review of 512 cases in a single institute. Surg Endosc 2012 A pr; 26(4):948-955.

\section{ABOUT THE AUTHORS}

\section{Gyan Chand (Corresponding Author)}

A ssociate Professor, Department of Endocrine Surgery, Sanjay Gandhi Postgraduate Institute of M edical Sciences, L ucknow, Uttar Pradesh India, Phone: +91-9451546353, e-mail: gyan133@sgpgi.ac.in

\section{Amit Agarwal}

Professor, Department of Endocrine Surgery, Sanjay Gandhi Postgraduate Institute of M edical Sciences, L ucknow, Uttar Pradesh, India 